\title{
SCIENTIFIC REPORTS

\section{Iron oxide nanocatalyst with titanium and silver nanoparticles: Synthesis, characterization and photocatalytic activity on the degradation of Rhodamine $B$ dye}

\author{
Pâmela Cristine Ladwig Muraro ${ }^{1}$, Sérgio Roberto Mortari ${ }^{1}$, Bruno Stefanello Vizzotto ${ }^{1}$, \\ Gabriela Chuy ${ }^{1}$, Cristiane dos Santos ${ }^{2}$, Luís Fernando Wentz Brum ${ }^{2}$ \& \\ William Leonardo da Silva ${ }^{1 *}$
}

Nowadays, there is a growing concern about the environmental impacts of colored wastewater. Thus, the present work aims the synthesis, characterization and determination of photocatalytic activity of iron oxide $\left(\mathrm{Fe}_{2} \mathrm{O}_{3}\right)$ nanocatalyst, evaluating the effect of hybridization with titanium (TiNPs- $\mathrm{Fe}_{2} \mathrm{O}_{3}$ ) and silver ( $\mathrm{AgNPs}-\mathrm{Fe}_{2} \mathrm{O}_{3}$ ) nanoparticles, on the degradation of Rhodamine $\mathrm{B}$ dye $(\mathrm{RhB})$. Nanocatalysts were characterized by XRD, SEM, TEM, FTIR, $\mathrm{N}_{2}$ porosimetry (BET/BJH method), zeta potential and DRS. Photocatalytic tests were performed in a slurry reactor, with the nanocatalyst in suspension, using RhB as a target molecule, under ultraviolet (UV) and visible radiation. Therefore, the photocatalytic activity of the nanocatalysts (non-doped and hybridized) was evaluated in these ideal conditions, where the AgNPs $-\mathrm{Fe}_{2} \mathrm{O}_{3}$ sample showed the best photocatalytic activity with a degradation of $94.1 \%(\mathrm{k}=0.0222$ $\mathrm{min}^{-1}$, under UV) and $58.36 \%\left(\mathrm{k}=0.007 \mathrm{~min}^{-1}\right.$, under visible), while under the same conditions, the $\mathrm{TiO}_{2}-\mathrm{P} 25$ commercial catalyst showed a degradation of $61.5 \%\left(\mathrm{k}=0.0078 \mathrm{~min}^{-1}\right)$ and $44.5 \%(\mathrm{k}=0.0044$ $\mathrm{min}^{-1}$ ), respectively. According with the ideal conditions determined, reusability of the $\mathrm{AgNPs}-\mathrm{Fe}_{2} \mathrm{O}_{3}$ nanocatalyst was measured, showing a short reduction (about $8 \%$ ) of its photocatalytic activity after 5 cycles. Thus, the $\mathrm{Fe}_{2} \mathrm{O}_{3}$ nanocatalyst can be considered a promising catalyst in the heterogeneous photocatalysis for application in the degradation of organic dyes in aqueous solution.

Dyes are substances with high application potential in the most diverse areas, mainly to color the final products of textile, precious stones, leather, paper, plastics and food. For example, it is estimated that there are more than 100,000 synthetic dyes, with an annual production of more than 700,000 tons worldwide, generating a significant amount of wastewater ${ }^{1}$. In addition, these colored waters are characterized by complex aromatic compounds, making their biodegradation difficult, becoming an environmental liability. Thus, advanced processes are needed to promote their correct treatment in order to meet environmental norms and legislation ${ }^{2}$.

In this context, the Advanced Oxidative Processes (AOPs), highlighting the heterogeneous photocatalysis, becomes an attractive alternative, since they are technologies with potential to oxidize a great variety of complex organic compounds ${ }^{3}$, using a highly oxidant and less selective species (the hydroxyl radical, ${ }^{\bullet} \mathrm{OH}$ ), capable of mineralize many organic compounds ${ }^{4}$. Thus, the heterogeneous photocatalysis involves the photoactivation of a semiconductor (catalyst), under visible or ultraviolet radiation, with energy equal to or greater than band gap energy ${ }^{5}$, promoting oxy-reduction reactions on the catalytic surface and thus the degradation of organic pollutants.

Among the most used catalysts are titanium dioxide $\left(\mathrm{TiO}_{2}\right)$, cadmium sulfide $(\mathrm{CdS})$, zinc oxide $(\mathrm{ZnO})$, zinc sulphide $(\mathrm{ZnS})$, tungsten trioxide $\left(\mathrm{WO}_{3}\right)$, tin dioxide $\left(\mathrm{SnO}_{2}\right)$ and iron oxide III $\left(\mathrm{Fe}_{2} \mathrm{O}_{3}\right)^{6}$. However, these catalysts

${ }^{1}$ Universidade Franciscana - Programa de Pós-Graduação em Nanociências Rua Silva Jardim no 1323, Santa Maria, RS, 97010-491, Brasil. ${ }^{2}$ Instituto de Química - Universidade Federal do Rio Grande do Sul Av. Bento Gonçalves no 9500, Porto Alegre, RS, 91501-970, Brasil. *email: w.silva@ufn.edu.br 
generally present a low specific surface area and porosity, limiting intraparticle diffusion of organic pollutants, compromising its photocatalytic activity ${ }^{7-9}$.

Nanocatalyst has emerged as an alternative to increase catalytic efficiency, since it has advantages over commercial catalysts, such as higher specific surface area and porosity, making them with great potential application in heterogeneous photocatalysis ${ }^{10}$. One of the strategies used to increase the photocatalytic activity of nanocatalysts is the usage of hybridization with noble metal and metals, in order to reduce the recombination between photoelectrons/holes pairs and reducing the energy required to its photoactivation, allowing its application to visible radiation ${ }^{11-16}$. In addition, Rhodamine $\mathrm{B}$ dye $(\mathrm{RhB})\left(\mathrm{C}_{28} \mathrm{H}_{31} \mathrm{~N}_{2} \mathrm{O}_{3} \mathrm{Cl}\right)$, a highly water soluble organic cation dye, belongings to the class of xanthenes, whose contact with humans can cause irritation to the skin, airways and eyes $^{17}$. Moreover, it presents the chromophoric groups $(-\mathrm{C}=\mathrm{C}-/-\mathrm{C}=\mathrm{N}-)$, as well as a characteristic carcinogenicity and neurotoxicity activity.

In this context, the present work aims the synthesis, characterization and determination of photocatalytic activity of $\mathrm{Fe}_{2} \mathrm{O}_{3}$ nanocatalyst, hybridized with titanium nanoparticles (TiNPs) and silver nanoparticles (AgNPs) on the degradation of Rhodamine $\mathrm{B}(\mathrm{RhB})$ dye, under $\mathrm{UV}$ and visible radiation.

\section{Materials and Methods}

Synthesis of the $\mathrm{Fe}_{2} \mathrm{O}_{3}$ nanocatalyst. The synthesis of iron oxide nanocatalyst followed the chemical precipitation by sodium borohydride method, according to the literature ${ }^{18}$. Sodium borohydride $\left(\mathrm{NaBH}_{4}, 0.2 \mathrm{~mol}\right.$ $\mathrm{L}^{-1}$, Neon, $\left.\mathrm{PA}\right)$ and ferric chloride hexahydrate $\left(\mathrm{FeCl}_{3} \cdot \mathrm{H}_{2} \mathrm{O}, 0.05 \mathrm{~mol} \mathrm{~L}{ }^{-1}\right.$, Synth, $\left.\mathrm{PA}\right)$ were mixed for 30 minutes, under magnetic stirring $(250 \mathrm{rpm})$. After, the synthesized nanoparticles were vacuum filtered and washed with deionized water and diluted ethanol $(\sim 5 \%)$. Parameters such as $\mathrm{pH}(\approx 7)$, reagents concentrations, stirring speed, reaction time and temperature $\left(23 \pm 0.5^{\circ} \mathrm{C}\right)$ were kept constant in order to avoid influence on the composition and properties of nanocatalyst.

Synthesis of nanoparticles (NPs). For silver nanoparticles (AgNPs), $75 \mathrm{~mL}$ of sodium borohydride solution $\left(0.002 \mathrm{~mol} \mathrm{~L}^{-1}\right.$, Neon, PA) was added, in ice bath, under for magnetic stirring for 10-15 min. with $25 \mathrm{~mL}$ of a silver nitrate solution $\left(0.001 \mathrm{~mol} \mathrm{~L}^{-1}\right.$, Synth, PA) (rate of $\left.1 \mathrm{drop} \mathrm{s}^{-1}\right)$, forming silver nanoparticles. It is noteworthy that titanium nanoparticles were commercially purchased $\left(\mathrm{TiO}_{2}\right.$, Evonik Aeroxide P25).

Synthesis of hybridized nanocatalyst. For hybridization of $\mathrm{Fe}_{2} \mathrm{O}_{3}$ nanocatalyst, the impregnation methodology was used with TiNPs and AgNPs, according to the literature ${ }^{19}$. Samples were magnetic stirring at room temperature for $90 \mathrm{~min}$, after calcined at $450^{\circ} \mathrm{C}$ (heating rate $10^{\circ} \mathrm{C} \mathrm{min}{ }^{-1}$ ) for 4 hours. Finally, the granulometry was standardized with milling and sieving (\#12). Hybridized nanocatalysts with NPs were labeled as TiNPs- $\mathrm{Fe}_{2} \mathrm{O}_{3}$ and AgNPs- $\mathrm{Fe}_{2} \mathrm{O}_{3}$, respectively.

Characterization of nanocatalyst. X-ray diffraction (XRD) was used to determine the crystallinity of the

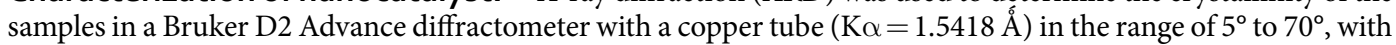
tension acceleration and applied current of $30 \mathrm{kV}$ and $30 \mathrm{~mA}$, respectively.

For zeta potential (PZ), Malvern-Zetasizer ${ }^{\circledR}$ model nanoZS (ZEN3600, UK) with closed capillary cells (DTS 1060) (Malvern, UK) was used to measure the zeta potential values of the samples.

$\mathrm{N}_{2}$ porosimetry was used to evaluate the textural properties of specific surface area $\left(\mathrm{S}_{\mathrm{BET}}\right)$ and porosity (pore diameter - Dp and pore volume - Vp) using in an equipment Gemini VII 2375 Surface Area Analyzer Micromeritics ${ }^{\circledR}$ and BET/BJH Methods $\left(\mathrm{P} \mathrm{Po}^{-1}=0.05-0.35\right)$.

Band gap energy was determined by diffuse reflectance spectroscopy at UV radiation (UV DRS) using a Varian Cary Scan Spectrophotometer with DRA-CA-301 accessory (Labsphere) coupled in the diffuse reflectance mode to determine the energy band gap by means of the Kubelka-Munk function with scans ranged from 200 to $600 \mathrm{~nm}$.

Scanning electron microscopy (SEM) and Transmission electronic microscopy (TEM) were used to morphologically characterize the nanocatalysts $\left(\mathrm{Fe}_{2} \mathrm{O}_{3}\right.$, TiNPs- $\mathrm{Fe}_{2} \mathrm{O}_{3}$ and AgNPs- $\left.\mathrm{Fe}_{2} \mathrm{O}_{3}\right)$ using a JSM5800 (JEOL) and JEM 1200 Exll (JEOL) microscope, respectively. Moreover, the samples were coated with a thin layer of conductive gold by a sputtering technique.

Effect of the photolysis and adsorption on the RhB degradation. To evaluate the influence of adsorption on degradation of $\mathrm{RhB}$ dye, were carried out preliminary tests (time $=90 \mathrm{~min}, \mathrm{pH} \approx 4.03$, $\left[\mathrm{Fe}_{2} \mathrm{O}_{3}\right]=0.7 \mathrm{~g} \mathrm{~L}^{-1}$ and $[\mathrm{RhB}]=20 \mathrm{mg} \mathrm{L}^{-1}$ ) in dark (without irradiation) conditions to establish the time required for the equilibrium of $\mathrm{RhB}$ molecule on nanocatalyst surface. Moreover, the effect of photolysis on $\mathrm{RhB}$ degradation was carried out by tests without catalyst, only under radiation with RhB dye solution $\left(20 \mathrm{mg} \mathrm{L}^{-1}\right.$, $61.8 \mathrm{~W} \mathrm{~m}^{-2}$ for UV irradiation and $202 \mathrm{~W} \mathrm{~m}^{-2}$ for visible irradiation and time $=60 \mathrm{~min}$ ).

Photocatalytic activity. Photodegradation tests were carried out using a solution of RhB, as the target molecule, and nanocatalysts in suspension (slurry). Tests were performed in two stages: (a) dark stage (absence of radiation), where adsorption/desorption equilibrium of the target molecule occurred on the surface of the nanocatalyst, with a duration of 60 minutes, and (b) a photocatalytic reaction step (with visible or UV radiation) with duration of 120 minutes (collections at predetermined times of $(0,5,15,30,45,60,75,90$, and 120 minutes). Then the samples were centrifuged (Cientec CT-5000R refrigerated centrifuge) for 20 minutes with a rotation of $5,000 \mathrm{rpm}$ and finally diluted $(1: 10 \mathrm{v} / \mathrm{v})$. 


\begin{tabular}{|l|l|l|l|}
\hline Order & {$[\mathbf{R h B}]\left(\mathrm{mg} \mathrm{L}^{-1}\right)$} & {$\left[\mathrm{Fe}_{2} \mathrm{O}_{3}\right]\left(\mathrm{g} \mathrm{L}^{-1}\right)$} & $\mathbf{p H}$ \\
\hline$(-1.68)$ & 5 & 0.5 & 2 \\
\hline$(-1)$ & 24.25 & 1.41 & 4.03 \\
\hline 0 & 52.5 & 2.75 & 7 \\
\hline$(+1)$ & 80.74 & 4.08 & 9.97 \\
\hline$(+1.68)$ & 100 & 5 & 12 \\
\hline
\end{tabular}

Table 1. Factorial planning matrix $2^{3}$ for $\mathrm{Fe}_{2} \mathrm{O}_{3}$ nanocatalyst.

\begin{tabular}{|l|l|l|l|l|l|}
\hline Samples & $\mathbf{S}_{\text {BET }}\left(\mathbf{m}^{\mathbf{2}} \mathbf{g}^{-1}\right)$ & $\mathbf{V p}\left(\mathbf{c m}^{\mathbf{3}} \mathbf{g}^{-\mathbf{1}}\right)$ & $\mathbf{D p}(\mathbf{n m})$ & $\mathbf{E g}(\mathbf{e V})$ & $\mathbf{Z P}(\mathbf{m V})$ \\
\hline $\mathrm{TiO}_{2}(\mathrm{P} 25)$ & 56 & 0.07 & 4.8 & 3.2 & -24.0 \\
\hline $\mathrm{Fe}_{2} \mathrm{O}_{3}$ & 158 & 0.93 & 22.6 & 2.2 & -13.3 \\
\hline TiNPs- $\mathrm{Fe}_{2} \mathrm{O}_{3}$ & 304 & 0.02 & 2.9 & 2.0 & -11.5 \\
\hline AgNPs- $\mathrm{Fe}_{2} \mathrm{O}_{3}$ & 505 & 1.60 & 3.5 & 1.8 & -10.2 \\
\hline
\end{tabular}

Table 2. Surface area $\left(S_{\mathrm{BET}}\right)$, pore volume $(\mathrm{Vp})$, pore diameter $(\mathrm{Dp})$, band gap energy $(\mathrm{Eg})$ and zeta potential (PZ) of the synthesized nanocatalysts.

Moreover, the absorbance measurements of solutions collected during reactions were carried out in a double-beam spectrophotometer (Varian, Cary 100) with a halogen lamp at the wavelength characteristic of RhB $(\lambda=553 \mathrm{~nm})$

Kinetic study of RhB degradation. In order to determine the specific reaction rate (k), a kinetic study of $\mathrm{RhB}$ dye degradation, under UV and visible radiation over time, was carried out according to the classic heterogeneous kinetic model (pseudo first-order model) (Eqs. 1 and 2) ${ }^{20,21}$ :

$$
-r_{i}=-\frac{d C_{i}}{d t}=\frac{k_{S} \cdot K \cdot C_{i}}{1+K \cdot C_{i}}
$$

Or:

$$
\ln \left(\frac{C_{i o}}{C_{i}}\right)=k_{S} \cdot K \cdot t=k \cdot t \text { or } C_{i}=C_{i o} \cdot e^{-k \cdot t}
$$

Experimental designs. Central Rotatable Composite Design (CRCD) (Statistic 8.0, StatSoft, Tulsa, OK, USA) symmetrical and of second order was used to determine the ideal reaction conditions ( $\mathrm{pH},[\mathrm{RhB}]$ and $\left[\mathrm{Fe}_{2} \mathrm{O}_{3}\right]$ ) for the degradation of $\mathrm{RhB}$ dye, constituted of a factorial $2^{3}$, with 8 tests, 3 central points, and 6 axial points, totalizing 17 experiments, according to Table 1.

\section{Results and Discussion}

Characterization of nanocatalysts. Table 2 shows the results of $\mathrm{N}_{2}$ porosimetry, DRS and zeta potential characterization.

According to Table 2, AgNPs- $\mathrm{Fe}_{2} \mathrm{O}_{3}$ showed the highest $\mathrm{S}_{\mathrm{BET}}\left(505 \mathrm{~m}^{2} \mathrm{~g}^{-1}\right)$, while TiNPs- $\mathrm{Fe}_{2} \mathrm{O}_{3},\left(304 \mathrm{~m}^{2} \mathrm{~g}^{-1}\right)$, while $\mathrm{Fe}_{2} \mathrm{O}_{3}\left(158 \mathrm{~m}^{2} \mathrm{~g}^{-1}\right)$ and $\mathrm{TiO}_{2}$ (P25) (56 $\left.\mathrm{m}^{2} \mathrm{~g}^{-1}\right)$ nanocatalysts. In relation to pore volume (Vp), AgNPs- $\mathrm{Fe}_{2} \mathrm{O}_{3}$ showed the highest volume $\left(1.6 \mathrm{~cm}^{3} \mathrm{~g}^{-1}\right)$. In addition, according to pore diameter (Dp), all nanocatalysts (non-doped and doped) showed mesoporous characteristics ${ }^{22}$. For heterogeneous photocatalysis, surface area and porosity (pore volume and diameter) are factors that directly affect photocatalytic performance, since they affect the adsorption of the target molecule and oxy-reduction reactions for hydroxyl radical formation ${ }^{23,24}$.

The band gap of $\mathrm{Fe}_{2} \mathrm{O}_{3}$, TiNPs- $\mathrm{Fe}_{2} \mathrm{O}_{3}$ and $\mathrm{AgNPs}-\mathrm{Fe}_{2} \mathrm{O}_{3}$ were found between 2.2; 2.0 and $1.8 \mathrm{eV}$, respectively. Thus, nanoparticles (NPs) promoted a reduction in conduction and valence bands, compared to $\mathrm{Fe}_{2} \mathrm{O}_{3}$ nanocatalyst, generating a decrease in the energy required for photoactivation of the hybridized nanocatalysts and shifting the application of nanocatalysts to the visible region of radiation ${ }^{25}$.

Moreover, all samples showed a negative charge surface potential $(-10.25$ to $-13.30 \mathrm{mV})$, according to zeta potential, indicating a charge compatibility, since $\mathrm{RhB}$ dye is characterized by its cationic nature ${ }^{26,27}$, increasing the $\mathrm{RhB}$ adsorption capacity on the catalytic surface and thus a possible better photocatalytic activity.

Figure 1 shows the X-ray diffractograms of the synthesized samples (without and with NPs hybridization).

According to Fig. 1, it is possible to identify the characteristic peaks of the photo phase of $\mathrm{TiO}_{2}$ (anatase) at $25.2^{\circ} ; 37.8^{\circ} ; 48.2^{\circ} ; 53.8^{\circ}$ e $55.0^{\circ}$ corresponding respectively to the plans (101), (004), (200), (105), e (211); some rutile diffraction peaks are still observed, the main one being $2 \theta=27.4^{\circ}$ which corresponds to the plane (110), according to JCPDS (Code 21-1272) ${ }^{28}$. Moreover, the silver nitrate X-ray diffraction pattern $\left(\mathrm{AgNO}_{3}\right)$ showed the characteristic peaks, with their respective crystalline planes, at $30.2^{\circ}(001), 35.6^{\circ}(111), 43.6^{\circ}(200)$ and $62.3^{\circ}$ $(220)^{29}$. In addition, it was possible to identify peaks of $\mathrm{Fe}_{2} \mathrm{O}_{3}$ oxide $\left(33.2^{\circ}, 35.6^{\circ}, 40.9^{\circ}, 54.1^{\circ}, 62.5^{\circ}\right.$ and $\left.64.1^{\circ}\right)$ 


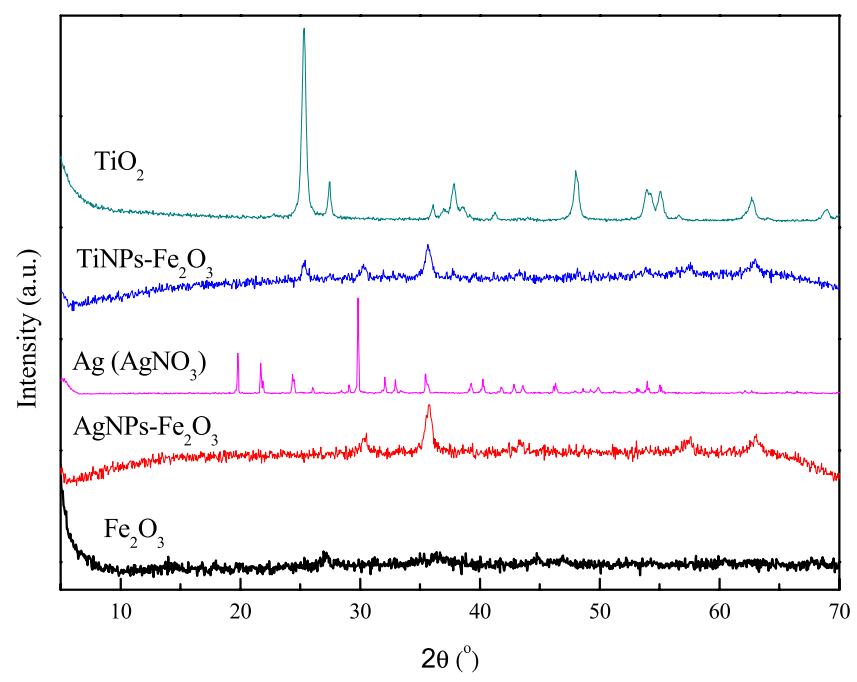

Figure 1. X-ray diffraction of nanocatalysts, $\left(\mathrm{Fe}_{2} \mathrm{O}_{3}\right.$, TiNPs- $\mathrm{Fe}_{2} \mathrm{O}_{3}$ and $\left.\mathrm{AgNPS}-\mathrm{Fe}_{2} \mathrm{O}_{3}\right)$ and standard XRD $\left(\mathrm{TiO}_{2}\right.$ and $\mathrm{AgNO}_{3}$ ).

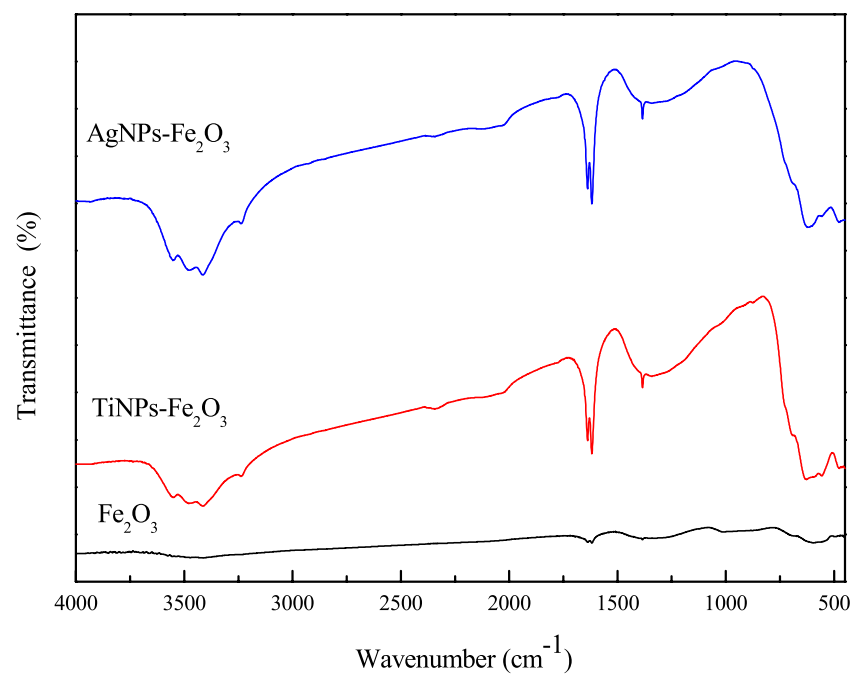

Figure 2. FTIR spectrum of nanocatalysts.

(JCPDS - Code 01-1053) ${ }^{30,31}$. Thus, the hybridization process with the NPs did not promote the formation of new peaks, as well as titanium and silver characteristic peaks were identified on $\mathrm{Fe}_{2} \mathrm{O}_{3}$ sample, indicating a successful hybridization.

FTIR analysis was used as a qualitative analysis technique to determine the functional groups present in the synthesized materials, according to Fig. 2.

According to Fig. 2, iron oxide showed at $3394 \mathrm{~cm}^{-1}$ strip, is attributed to stretch vibrations ( $\nu$ ), while the $1620 \mathrm{~cm}^{-1}$ strip is attributed to flexural vibrations $(\delta)$ due to water adsorbed on the surface of the iron oxide nanoparticles ${ }^{32}$. The band observed at $611 \mathrm{~cm}^{-1}$ corresponds to the stretching vibrations of $\mathrm{M}_{\mathrm{Th}}-\mathrm{O}-\mathrm{M}_{\mathrm{Oh}}$, where $\mathrm{M}_{\mathrm{Th}}$ and $\mathrm{M}_{\mathrm{Oh}}$ correspond to iron occupying tetrahedral and octahedral positions, respectively. TiNPs showed at $590 \mathrm{~cm}^{-1} \mathrm{due}^{-}$ to the vibration of the $\mathrm{TiO}-\mathrm{O}$ bond $\mathrm{d}^{33,34}$.

Figure 3 shows SEM micrographs of the nanocatalysts (a) $\mathrm{Fe}_{2} \mathrm{O}_{3}$, (b) TiNPs- $\mathrm{Fe}_{2} \mathrm{O}_{3}$ and (c) $\mathrm{AgNPs}-\mathrm{Fe}_{2} \mathrm{O}_{3}$, while Fig. 3(d,e) show the TEM micrographs of the TiNPSs- $\mathrm{Fe}_{2} \mathrm{O}_{3}$ and $\mathrm{AgNPs}-\mathrm{Fe}_{2} \mathrm{O}_{3}$ samples, respectively. Then, it was possible to identify a heterogeneous surface with a random distribution of the TiNPs and AgNPs, with the formation of small clusters of NPs. Then, it can be explained through of the zeta potential (surface charge), since using NPs, the ZP showed a smaller between the nanoparticles, causing a lower dispersion, in relation to $\mathrm{Fe}_{2} \mathrm{O}_{3}$ nanocatalyst (with higher value of $\mathrm{ZP})^{33}$. Thus, this greater dispersion of NPs tends to promote changes in the textural properties of nanocatalysts, such as an improve of the specific area and a greater number of active sites to conductive the RhB adsorption, directly affecting photocatalytic activity ${ }^{34}$. Therefore, TEM micrographs showed the presence of NPs (TiNPs and AgNPs) over $\mathrm{Fe}_{2} \mathrm{O}_{3}$ in spherical shape with a diameter around $3 \mathrm{~nm}$. 


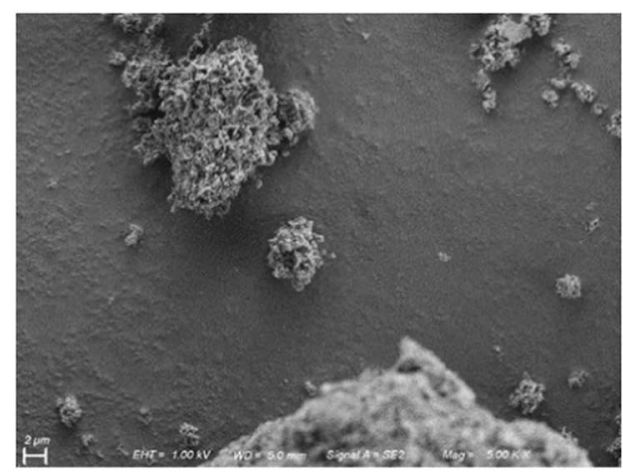

(a)

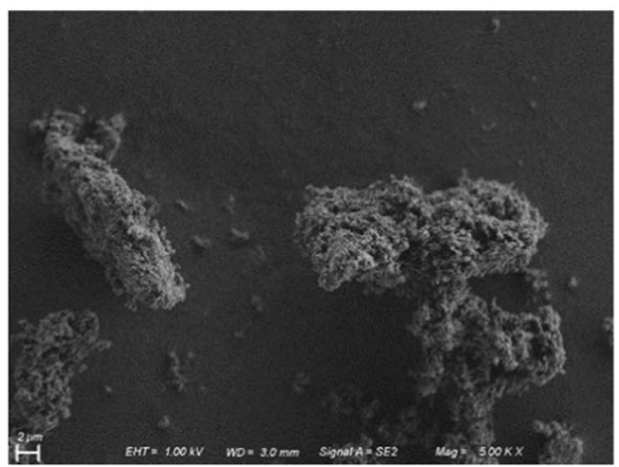

(c)

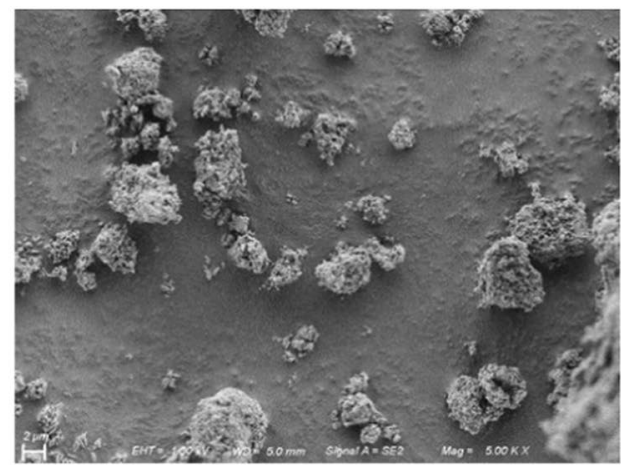

(b)

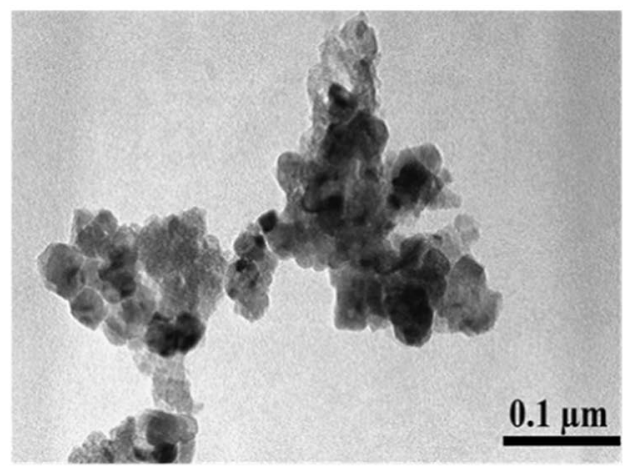

(d)

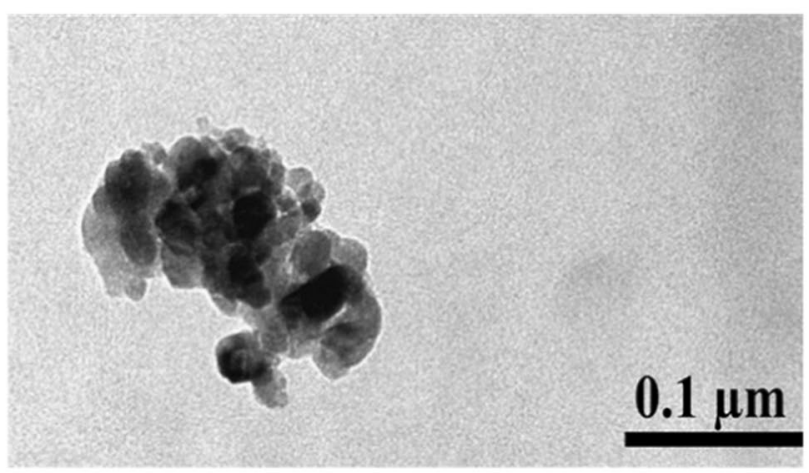

(e)

Figure 3. SEM micrographs for the samples: (a) $\mathrm{Fe}_{2} \mathrm{O}_{3}$, (b)TiNPs- $\mathrm{Fe}_{2} \mathrm{O}_{3}$ and (c) AgNPs- $\mathrm{Fe}_{2} \mathrm{O}_{3}$, and TEM micrographs for the (d) TiNPs- $\mathrm{Fe}_{2} \mathrm{O}_{3}$ and (e) AgNPs- $\mathrm{Fe}_{2} \mathrm{O}_{3}$.

Adsorption and photolysis. Preliminary tests of the adsorption showed that the minimum time necessary for the adsorption equilibrium of RhB was 60 minutes, with an adsorption percentage of $4.71,8.70$ and $10.32 \%$ to $\mathrm{Fe}_{2} \mathrm{O}_{3}$, TiNPs- $\mathrm{Fe}_{2} \mathrm{O}_{3}$ and AgNPs- $\mathrm{Fe}_{2} \mathrm{O}_{3}$, respectively. The preliminary tests of photolysis indicated that only $14 \%$ (UV radiation) and $4 \%$ (visible radiation) of $\mathrm{RhB}$ were degraded after 60 minutes.

Central rotatable composite design. Figure 4 shows the Pareto chart used to evaluate the main effects of the central rotatable composite design ( $\mathrm{pH},[\mathrm{RhB}]$ and $\left.\left[\mathrm{Fe}_{2} \mathrm{O}_{3}\right]\right)$. The reduced quadratic model (Eq. (3)) represents the $\mathrm{Fe}_{2} \mathrm{O}_{3}$ CRCD experiments, in which " $y$ " represents the dependent variable (percentage of photocatalytic degradation after 120 minutes).

$$
y=59.84+10.26 \cdot p H-11.82 .[R h B]
$$

According to Fig. 4, the $\mathrm{RhB}$ concentration showed a negative effect, thus with increasing $\mathrm{RhB}$ concentration occurs a reduction of the photocatalytic activity on $\mathrm{RhB}$ degradation occurs due to the reduction in the number of active sites available for adsorption on surface of $\mathrm{Fe}_{2} \mathrm{O}_{3}$ the nanocatalyst ${ }^{35}$. About the effect of $\mathrm{pH}$, it has a positive effect on $\mathrm{RhB}$ degradation, since with the increase of the $\mathrm{pH}$, the surface of $\mathrm{Fe}_{2} \mathrm{O}_{3}$ nanocatalyst is more deprotonated, increasing the compatibility of charges between $\mathrm{RhB}$ and $\mathrm{Fe}_{2} \mathrm{O}_{3}$ and thus increasing adsorption and photocatalytic activity ${ }^{36}$. 


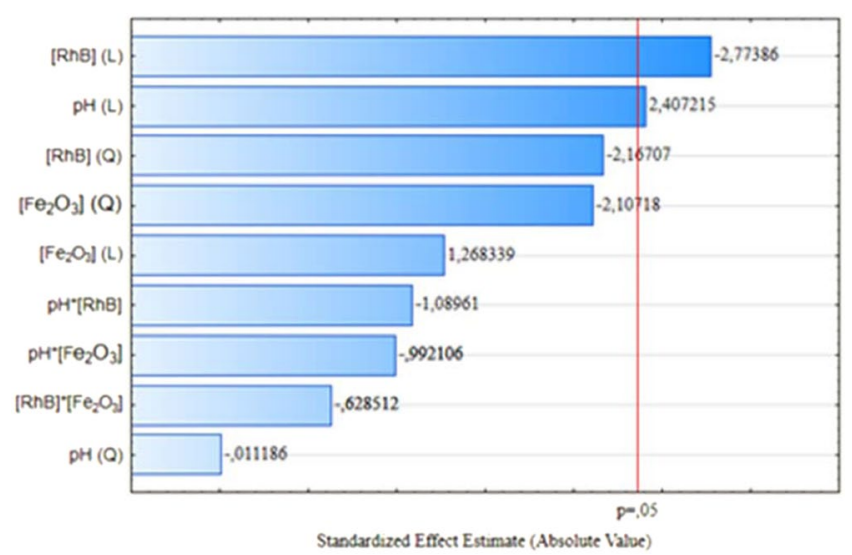

Figure 4. Pareto chart on the effect of the $\mathrm{pH},[\mathrm{RhB}]$ and $\left[\mathrm{Fe}_{2} \mathrm{O}_{3}\right]$ on the degradation of $\mathrm{RhB}$ dye.

Therefore, after all the photocatalytic tests, the ideal conditions determined were $1.41 \mathrm{~g} \mathrm{~L}^{-1}$ to $\mathrm{Fe}_{2} \mathrm{O}_{3}$ nanocatalyst, $24.25 \mathrm{mg} \mathrm{L}^{-1} \mathrm{RhB}$ concentration and $\mathrm{pH}=9.97$, which showed the greatest degradation of the $77.38 \%$, after 120 minutes under UV radiation.

Photocatalytic performance. The photocatalytic performance of nanocatalysts $\left(\mathrm{Fe}_{2} \mathrm{O}_{3}, \mathrm{TiNPs}_{2} \mathrm{Fe}_{2} \mathrm{O}_{3}\right.$ and AgNPs- $\mathrm{Fe}_{2} \mathrm{O}_{3}$ ) was evaluated by the photodegradation of $\mathrm{RhB}$, under UV and visible radiation, using the ideal conditions.

After $120 \mathrm{~min}$ of UV radiation, $77.38 \%\left(\mathrm{k}=0.0124 \mathrm{~min}^{-1}\right), 88.03 \%\left(\mathrm{k}=0.0173 \mathrm{~min}^{-1}\right)$ and $94.10 \%(\mathrm{k}=0.022$ $\left.\mathrm{min}^{-1}\right)$ of $\mathrm{RhB}$ were degraded using $\mathrm{Fe}_{2} \mathrm{O}_{3}$, TiNPs- $\mathrm{Fe}_{2} \mathrm{O}_{3}$ and $\mathrm{AgNPs}-\mathrm{Fe}_{2} \mathrm{O}_{3}$, while $38.03 \%\left(\mathrm{k}=0.0039 \mathrm{~min}^{-1}\right)$, $48.36 \%\left(\mathrm{k}=0.0055 \mathrm{~min}^{-1}\right)$ and $58.36 \%\left(\mathrm{k}=0.0070 \mathrm{~min}^{-1}\right)$ of $\mathrm{RhB}$ were degraded using $\mathrm{Fe}_{2} \mathrm{O}_{3}, \mathrm{TiNPs}-\mathrm{Fe}_{2} \mathrm{O}_{3}$ and AgNPs- $\mathrm{Fe}_{2} \mathrm{O}_{3}$ under visible radiation, respectively, according to Fig. 5.

According to Fig. 5, the hybridization of $\mathrm{Fe}_{2} \mathrm{O}_{3}$ nanocatalyst with NPs (TiNPs and AgNPs) promoted an increase in the photocatalytic activity on the $\mathrm{RhB}$ degradation under $\mathrm{UV}$ radiation $\left(13.8 \%\right.$ using to TiNPs- $\mathrm{Fe}_{2} \mathrm{O}_{3}$ and $21.6 \%$ with AgNPs- $\mathrm{Fe}_{2} \mathrm{O}_{3}$ ) and visible radiation (27.2\% - TiNPs- $\mathrm{Fe}_{2} \mathrm{O}_{3}$ and $55.4 \%-\mathrm{AgNPs}-\mathrm{Fe}_{2} \mathrm{O}_{3}$ ). This can be explained, due the fact that the nanoparticles (TiNPs and AgNPs) can act as electron traps facilitating the electron hole separation and subsequent transference of trapped electrons to the absorbed $\mathrm{O}_{2}$ acting as an electron acceptor on the surface of $\mathrm{Fe}_{2} \mathrm{O}_{3}$ nanocatalyst ${ }^{35,36}$. Thus, more molecules are adsorbed on the surface of hybridized nanocatalysts, enhancing the photo excited electron to the conduction band and simultaneously increasing the electron transfer to the adsorbed $\mathrm{O}_{2}$.

The power of the semiconductor material to act as a sensitizer and to enhance the photodegradation of the $\mathrm{RhB}$ is based on their electronic structure with filled valence bond and empty conduction bond ${ }^{37}$. The semiconductor photooxidation instigated the photocatalysis of $\mathrm{RhB}$ in solution, leaving the catalyst surface with a strong oxidative potential of an electron-hole pair $\left(\mathrm{h}^{+}{ }_{\mathrm{VB}}\right)$ (Eq. (4)), when photocatalyst was irradiated with higher energy than that of band gap energy $(\mathrm{Eg})$, which allows the oxidation of the $\mathrm{RhB}$ molecule in a direct manner to the reactive intermediates (Eq. (5)). The hydroxyl radical $\left(\mathrm{OH}^{\bullet}\right)$, the exceptionally strong and a non-selective oxidant which is formed either by decomposition of water (Eq. (6)) or by reaction of hole along with hydroxyl ion $\left(\mathrm{OH}^{-}\right)$(Eq. (7)) is also responsible for degradation of phenol molecule. Leading to incomplete or complete mineralization of many organic molecules (Eq. (8) $)^{38}$.

$$
\begin{gathered}
\mathrm{NPs}-\mathrm{Fe}_{2} \mathrm{O}_{3}+h \nu \rightarrow \mathrm{NPs}-\mathrm{Fe}_{2} \mathrm{O}_{3}\left(e_{\mathrm{CB}}^{-}+h_{V B}^{+}\right) \\
\left(h_{V B}^{+}\right)+\mathrm{RhB} \rightarrow \mathrm{RhB}^{\bullet+} \rightarrow \text { oxidation of RhB molecule } \\
\left(h_{V B}^{+}\right)+\mathrm{H}_{2} \mathrm{O} \rightarrow \mathrm{H}^{+}+\mathrm{HO}^{\bullet} \\
\left(h_{V B}^{+}\right)+\mathrm{HO}^{-} \rightarrow \mathrm{HO}^{\bullet} \\
H \mathrm{O}^{\bullet}+\mathrm{RhB} \rightarrow \text { degradation of } \mathrm{RhB} \text { molecules }
\end{gathered}
$$

Effect of AgNPs- $\mathrm{Fe}_{2} \mathrm{O}_{3}$ recycling. The effect of reuse of the $\mathrm{AgNPs}-\mathrm{Fe}_{2} \mathrm{O}_{3}$ nanocatalyst under visible radiation $\left(202 \mathrm{~W} \mathrm{~m}^{-2}\right)$ was evaluated in 5 times, according to Table 3.

According to Table 3, the AgNPS- $\mathrm{Fe}_{2} \mathrm{O}_{3}$ nanocatalyst showed a photostability after five recycling processes, with a small decrease (about $8 \%$ ) in the photocatalytic activity (58.36\% to $53.69 \%$ ), under visible radiation. 


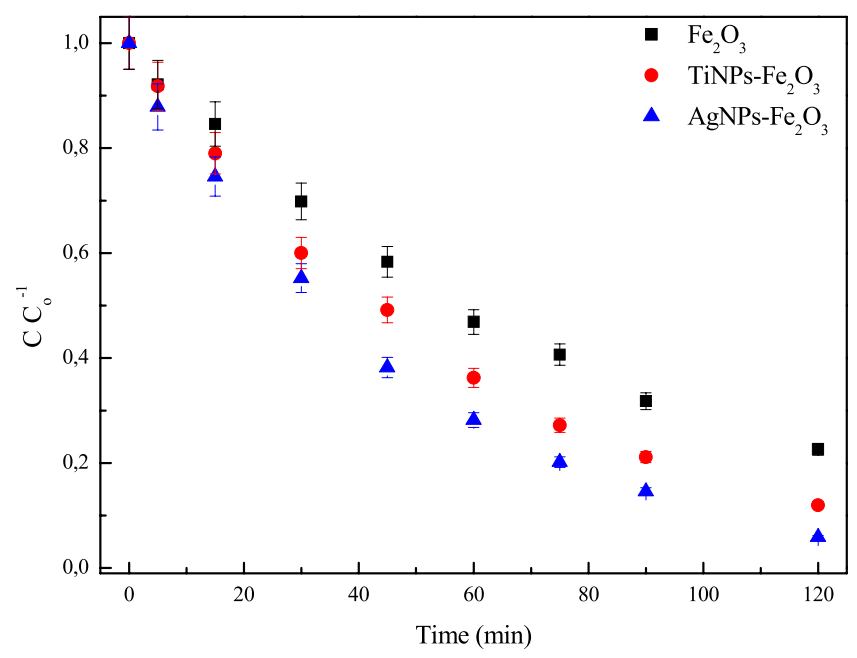

(a)

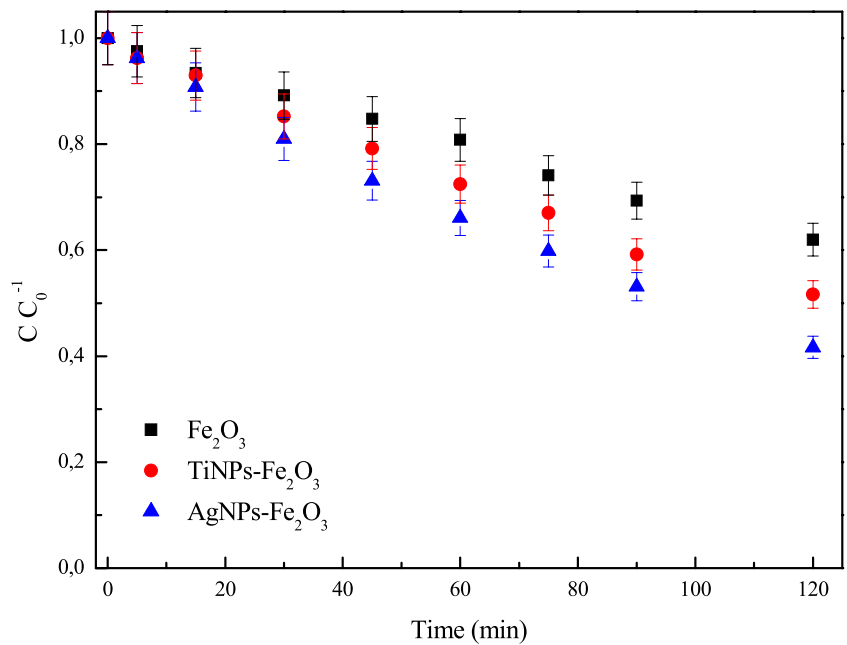

(b)

Figure 5. Photocatalytic activity of nanocatalysts $\left(\mathrm{Fe}_{2} \mathrm{O}_{3}\right.$, TiNPs- $\mathrm{Fe}_{2} \mathrm{O}_{3}$ and $\left.\mathrm{AgNPs}-\mathrm{Fe}_{2} \mathrm{O}_{3}\right)$ on $\mathrm{RhB}$ degradation under UV (a) and visible (b) radiation after 120 minutes ([catalyst] $=1.41 \mathrm{~g} \mathrm{~L}^{-1}$, $[\mathrm{RhB}]=24.25 \mathrm{mg} \mathrm{L}^{-1}$, $\mathrm{T}=30^{\circ} \mathrm{C}, \mathrm{pH}=9.97$, $\mathrm{UV}$ radiation of $61.8 \mathrm{~W} \mathrm{~m}^{-2}$, visible radiation of $202 \mathrm{~W} \mathrm{~m}^{-2}$ and error $5 \%$ ).

\begin{tabular}{|l|l|}
\hline Cycle number & Degradation (\%) \\
\hline Cycle I (fresh nanocatalyst) & 58.36 \\
\hline Cycle II & 57.40 \\
\hline Cycle III & 56.68 \\
\hline Cycle IV & 55.73 \\
\hline Cycle V & 54.39 \\
\hline Cycle VI & 53.69 \\
\hline
\end{tabular}

Table 3. Effect of AgNPs- $\mathrm{Fe}_{2} \mathrm{O}_{3}$ nanocatalyst reuse on degradation of the RhB.

\section{Conclusion}

According to the characterization and photocatalytic activity results, the hybridization process with NPs (TiNPs and AgNPs) caused positive changes in the properties of $\mathrm{Fe}_{2} \mathrm{O}_{3}$ nanocatalyst for heterogeneous photocatalysis, such as: reduction of band gap energy (2.2 eV to $2.0 \mathrm{eV}-\mathrm{TiNPs}-\mathrm{Fe}_{2} \mathrm{O}_{3}$ and $1.8 \mathrm{eV}-\mathrm{AgNPs}-\mathrm{Fe}_{2} \mathrm{O}_{3}$ ); increase of surface area $\left(158 \mathrm{~m}^{2} \mathrm{~g}^{-1}\right.$ to $304 \mathrm{~m}^{2} \mathrm{~g}^{-1}$ - TiNPs- $\mathrm{Fe}_{2} \mathrm{O}_{3}$ and $505 \mathrm{~m}^{2} \mathrm{~g}^{-1}-\mathrm{AgNPs}_{-} \mathrm{Fe}_{2} \mathrm{O}_{3}$ ) and increase in photocatalytic activity under UV and visible radiation. Therefore, nanoparticle hybridization on nanocatalysts is a great option to improve the photocatalytic performance for degradation of organic pollutants (such as dyes) by heterogeneous photocatalysis. 
Received: 17 November 2019; Accepted: 6 February 2020;

Published online: 20 February 2020

\section{References}

1. Al-Fawwaz, A. T. \& Abdullah, M. Decolorization of methylene blue and malachite green by immobilized Desmodesmus sp. isolated from North Jordan. Int. J. Environ. Sci. Dev. 7, 95-99 (2016).

2. De Araújo, K. S., Antonelli, R., Gaydeczka, B., Granato, A. C. \& Malpass, G. R. P. Advanced oxidation processes: a review of fundamentals and applications in the treatment of urban and industrial wastewaters. Rev. Ambient. Água 11, 1-15 (2016).

3. Ma, J., Li, L., Zou, J., Kong, Y. \& Komarneni, S. Highly efficient visible light degradation of Rhodamine B by nanophasic $\mathrm{Ag}_{3} \mathrm{PO}_{4}$ dispersed on SBA-15. Mat. Res. C 48, 154-159 (2014).

4. Pereira, V. J., Fernandes, D., Carvalho, G., Benoliel, M. J. \& San Romão, M. V. Assessment of the presence and dynamics of fungi in drinking water sources using cultural and molecular methods. Water Res. 44, 4850-4859 (2010).

5. Pirkanniemi, K. \& Sillanpää, M. Heterogeneous water phase catalysis as an environmental application: a review. Chemosphere 48, 1047-1060 (2002).

6. Wang, L., Zhao, J., Liu, H. \& Huang, J. Design, modification and application of semiconductor photocatalysts. J. Taiwan Inst. Chem. 93, 590-602 (2018).

7. Collivignarelli, M. C., Abbà, A., Miino, M. C. \& Damiani, S. Treatments for color removal from wastewater: State of the art. J. Environ. Manage. 236, 727-745 (2018).

8. Low, J., Yu, J., Jaroniec, M., Wageh, S. \& Al-Ghamdi, A. A. Heterojunction Photocatalysts. Adv. Mater. 29, 16016940 (2017).

9. Low, J., Cheng, B. \& Yu, J. Surface modification and enhanced photocatalytic $\mathrm{CO}_{2}$ reduction performance of TiO 2 : a review. Appl. Surf. Sci. 392, 658-686 (2017).

10. Silva, M. F., Pineda, E. A. G. \& Bergamasco, R. Application of nanostructured iron oxides as adsorbents and photocatalysts in the removal of pollutants from waste water. Quim. Nova 38, 393-398 (2015).

11. Einaga, H., Ibusuki, T. \& Futamura, S. Improvement of catalyst durability by deposition of $\mathrm{Rh}$ on $\mathrm{TiO}_{2}$ in photooxidation of aromatic compounds. Envir. Sci Tech. 38, 285-289 (2004).

12. Kozlova, E. A. \& Vorontsov, A. V. Nobel metal and sulfuric acid modified $\mathrm{TiO}_{2}$ photocatalyts: mineralization of organophorous compounds. Appl. Catal. B-Environ. 63, 114-123 (2006).

13. You, X. F., Chen, F., Zhang, J. \& Anpo, M. A novel deposition precipitation method for preparation of Ag-loaded titanium dioxide. Catal. Lett. 102, 247-250 (2005).

14. Wang, J., Liu, B. \& Nakata, K. Effects of crystallinity, $\{001\} /\{101\}$ ratio, and Au decoration on the photocatalytic activity of anatase $\mathrm{TiO}_{2}$ crystals. Chinese J. Catal. 40, 403-412 (2019).

15. Bui, V. K. H. et al. Synthesis of $\mathrm{MgAC}-\mathrm{Fe}_{3} \mathrm{O}_{4} / \mathrm{TiO}_{2}$ hybrid nanocomposites via sol-gel chemistry for water treatment by photo-Fenton and photocatalytic reactions. Sci. Rep. 9, 11855-711866 (2019).

16. Xu, W. et al. Fabrication of commercial pure Ti by selective laser melting using hydride-dehydride titanium powders treated by ball milling. J. Mater. Sci. Tech. 35, 322-327 (2019).

17. Gupta, V. K. \& Suhas, S. Application of low-cost adsorbents for dye removal - A review. J. Environ. Manage. 90, 2313-2342 (2009).

18. Sun, Y., Li, X., Cao, J., Zhang, W. \& Wang, H. P. Characterization of zero-valent iron nanoparticles. Adv. Colloid Interfac. 120, 47-56 (2006).

19. Melo, M. A. Jr., Santos, L. S. S., Gonçalves, M. C. \& Nogueira, A. F. Preparation of silver and gold nanoparticles: a simple method to introduce nanotechnology into teaching laboratories. Quim. Nova 35, 1872-1878 (2012).

20. Gogate, P. R. \& Pandit, A. B. A review of imperative technologies for wastewater treatment I: oxidation technologies at ambient conditions. Adv. Environ. Res. 8, 501-551 (2004)

21. Gaya, U. I. \& Abdullah, A. H. Heterogeneous photocatalytic degradation of organic contaminants over titanium dioxide: A review of fundamentals, progress and problems. J. Photoch. Photobio. C 9, 1-12 (2008).

22. IUPAC. Manual of symbols and Terminology. Pure Apll. Chem. 31, 578-592 (1972).

23. Bet-moushoul, E., Mansourpanah, Y., Farhadi, K. \& Tabatabaei, $\mathrm{M}$. $\mathrm{TiO}_{2}$ nanocomposite based polymeric membranes: A review on performance improvement for various applications in chemical engineering processes. Chem. Eng. J. 283, 29-46 (2016).

24. Vadivel, S. \& Rajarajan, G. Effect of Mg hybridization on structural, optical and photocatalytic activity of $\mathrm{SnO}_{2}$ nanostructure thin films. J. Mater Sci. Mater. 26, 3155-3162 (2015).

25. Debrassi, A., Largura, M. C. T. \& Rodrigues, C. A. Adsorption of Congo red dye by hydrophobic o-carboxymethyl chitosan derivatives. Quim. Nova 34, 764-770 (2011).

26. Salleh, M. A. M., Mahomoud, D. K., Karim, W. A. \& Idris, A. Cationic and anionic dye adsorption by agricultural solid wastes: A comprehensive review. Desalination 280, 1-13 (2011).

27. Jarlbring, M., Gunneriusson, L., Hussmann, B. \& Forsling, W. Surface complex characteristics of synthetic maghemite and hematite in aqueous suspensions. J. Colloid Interf. Sci. 285, 212-217 (2005).

28. Sansiviero, M. T. C. \& de Faria, D. L. A. Influence of thermal treatment on the photocatalyst nanocomposite $\mathrm{ZnO} / \mathrm{TiO}_{2}$. Quim. Nova 38, 55-59 (2015).

29. Boningari, T., Inturi, S. N. R., Suidan, M. \& Smirniotis, P. G. Novel continuous single-step synthesis of nitrogen-modified TiO by $^{2}$ flame spray pyrolysis for photocatalytic degradation of phenol in visible light. J. Mater. Sci. Tech. 34, 1494-1502 (2018).

30. Yu, X., Liu, S. \& Yu, J. Superparamagnetic $\gamma-\mathrm{Fe}_{2} \mathrm{O}_{3} @ \mathrm{SiO}_{2} @ \mathrm{TiO}_{2}$ composite microspheres with superior photocatalytic properties. Appl. Catal. B-Environ 104, 12-20 (2011).

31. Xie, T., Liu, Y., Wang, H. \& Wu, Z. Synthesis of $\alpha-\mathrm{Fe}_{2} \mathrm{O}_{3} / \mathrm{Bi}_{2} \mathrm{WO}_{6}$ layered heterojunctions by in situ growth strategy with enhanced visible-light photocatalytic activity. Sci. Rep. 9, 7551-7562 (2019).

32. Devi, L. B. \& Mandal, A. B. Self-assembly of Ag nanoparticles using hydroxypropyl cyclodextrin: synthesis, characterization and application for the catalytic reduction of p-nitrophenol. Rsc. Adv. 3, 5238-5253 (2013).

33. Kaleji, B. K., Sarraf-Mamorry, R., Nakata, K. \& Fujishima, A. The effect of Sn dopant on crystal structure and photocatalytic behavior of nanostructured titania thin films. J. Sol-Gel Sci. Techn. 60, 90-99 (2011).

34. Qamar, M. \& Muneer, M. A comparative photocatalytic activity of titanium dioxide and zinc oxide by investigating the degradation of vanillin. Desalination 249, 535-540 (2009).

35. Daneshvar, N., Aber, S., Dorraji, M. S., Khataee, A. R. \& Rasoulifard, M. H. Photocatalytic degradation of the insecticide diazinon in the presence of prepared nanocrystalline ZnO powders under irradiation of UV-C light. Sep. Purif. Technol. 58, 91-98 (2007).

36. Da Silva, W. L., Lansarin, M. A., Dos Santos, J. H. Z. \& Silveira, F. Photocatalytic degradation of Rhodamine B, paracetamol and diclofenac sodium by supported titania-based catalysts from petrochemical residue: effect of hybridization with magnesium. Water Sci. Technol. 74, 2370-2383 (2016).

37. Gnanaprakasam, A., Sivakumar, V. M. \& Thirumarimurugan, M. Influencing parameters in the photocatalytic degradation of organic effluent via nanometal oxide catalyst: A review. Indian J. Mater. Sci. 1, 1-16 (2015)

38. Kansal, S. K., Singh, M. \& Sud, D. Studies on photodegradation of two commercial dyes in aqueous phase using different photocatalysts. J. Hazard. Mater. 141, 581-590 (2007). 


\section{Acknowledgements}

We thank the Laboratory of Catalysis and Polymers (K106) of the Federal University of Rio Grande do Sul (UFRGS) and Nanotechnology Laboratory (S013) of the Franciscan University for the support and assistance to carry out the present work. Moreover, this work received financial support from the Foundation for Research of the State of Rio Grande do Sul (FAPERGS - Project 19/2551-0001362-0), so all thanks.

\section{Author contributions}

P. Muraro designed, performed most of the experiments and wrote the manuscript. S.R. Mortari, B.S. Vizzotto, G. Chuy, C. dos Santos, L.F.W. Brum and W.L. da Silva supervised the research work. All authors were contributed to discussion and writing the manuscript.

\section{Competing interests}

The authors declare no competing interests.

\section{Additional information}

Correspondence and requests for materials should be addressed to W.L.d.S.

Reprints and permissions information is available at www.nature.com/reprints.

Publisher's note Springer Nature remains neutral with regard to jurisdictional claims in published maps and institutional affiliations.

(c) (i) Open Access This article is licensed under a Creative Commons Attribution 4.0 International License, which permits use, sharing, adaptation, distribution and reproduction in any medium or format, as long as you give appropriate credit to the original author(s) and the source, provide a link to the Creative Commons license, and indicate if changes were made. The images or other third party material in this article are included in the article's Creative Commons license, unless indicated otherwise in a credit line to the material. If material is not included in the article's Creative Commons license and your intended use is not permitted by statutory regulation or exceeds the permitted use, you will need to obtain permission directly from the copyright holder. To view a copy of this license, visit http://creativecommons.org/licenses/by/4.0/.

(c) The Author(s) 2020 